\title{
基于SCI \& SSCI期刊《Urban Forestry \& Urban Greening》 探讨国际城市绿化研究动态
}

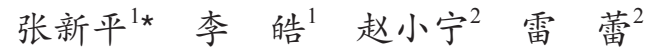 \\ 1. 西安理工大学艺术与设计学院, 陕西西安 710054 \\ 2. 商洛市气象局, 陕西商洛 726000
}

\begin{abstract}
摘 要: 从现状、热点与趋势等维度系统分析了国际城市绿化主导期刊《Urban Forestry \& Urban Greening》所发表 的1382篇文章的文献计量学特征。结果表明: 第一, 国际城市绿化研究文献量呈快速增长趋势, 学科交叉特征显著, 美 国、中国和欧洲部分国家是主要研究力量, 初步形成了国际合作网络; 第二, 凤景园林、雷达、治理、城镇化、重金 属、调研、城市规划、美学偏好是国际城市研究的主要关键词族群, 并识别出了热点关键词; 第三, 城市树木效益与成 本评估、城市绿化数值模型、社会生态学与城市绿化的结合为国际城市绿化研究的主要方向。未来研究应该加强国际合 作, 深化学科交叉, 紧贴生产实践, 关注使用者意见, 连通尺度上的断点, 共建数据平台和完善学科体系。
\end{abstract}

关键词：绿色空间；文献计量；热点分析；系统综述

\section{一、前言}

城市化是一个全球性的多维过程, 表现在人口密度的快速变化和土地覆盖的改变。城市扩张是四种力量共同作用 的结果, 即自然增长、农村向城市的人口流动、因极端事件的移民和行政区域的重新界定。目前, 世界总人口的一半居 住在城市, 预期这一比例在 50 年内可增至 $2 / 3$ 。如今有 300 多个城市的人口已超过 106 , 而其中 19 个特大城市的人口更是 超过107。随着城市化的推进, 城市的扩张形成了大型城市景观, 尤其是在发展中国家更为突出。城市化的生态影响体 现在以下三个维度: 第一, 物理和化学环境 (水、土、气被污染) ; 第二, 种群和群落特征 (繁殖率、进化选择、群体 行为、物种替代率、生活史对策等受影响) ; 第三, 生态系统结构和功能 (干扰机制、演替、分解率、养分保持力、生 境、营养结构、食物链等被改变) 。城市绿色空间与蓝色空间一起为应对城市化的生态影响, 提供一定效度的韧性和弹 力 $^{[1]}$ 。在城市环境中, 城市绿化是可持续性提供与维持生态系统服务能力的最有效途径 ${ }^{[2]}$, 一方面要科学合理地利用好 存量绿化用地, 另一方面又要通过城市恢复手段创造新的城市绿色空间, 如将棕地 (废弃的工业区、机场、填埋场等) 转变为功能性绿色用地 ${ }^{[3,4]}$ 。城市森林是城市区域内受惠最大的陆地生态系统和重要的绿色基础设施, 也是宜居城市的 重要标志 ${ }^{[5]}$ 。在紧凑城市概念的背景下, 城市绿地的规划和管理是一个关键问题, 需要考虑不同使用群体的需求, 需要 规划设计出涵盖休闲、社会互动、美学、文化遗产和生态服务等方面的多功能室内外绿色空间 ${ }^{[2]}$ 。城市绿化与社会、生 态、经济和技术系统均有密切联系, 因此, 城市绿化的研究呈现明显的多学科交叉特征, 全球各国对城市绿化的关注度 在不断提高。

《城市林业与城市绿化》 ( Urban Forestry \& Urban Greening, 简称UFUG), 是一本以城市和城市周边的木质和非 木质植被及其使用、规划、设计、建立和管理为主题的高质量研究的国际学术期刊。该期刊被 SCI (二区) 和SSCI同 时收录, 影响因子高达4.021, 在风景园林学科领域排名世界第二, 仅次于Landscape and Urban Planning。UFUG现由 香港大学地理系教授Wendy Y. Chen担任主编, 编委由全球城市林业与绿化领域相关的专业出色学者团队组成, 由此可 见, UFUG所刊载的学术论文代表着国际城市林业与城市绿化研究的前沿 ${ }^{[6]}$ 。

*通讯作者: 张新平, 1981 年5月, 男, 汉族, 陕西柞水人, 现任职于西安理工大学艺术与设计学院, 讲师, 风景 园林高级工程师, 博士。研究方向: 景观规划与遥感监测、景观生态、城市林业、景观与数据可视化。

基金项目: 商洛市气候适应型城市重点实验室开放研究基金（SLSYS2019002）：秦岭商洛段气候康养资源评估与 区划及康养效应研究; 2020年陕西省社会科学基金年度项目（2020N004）：黄河流域生态保护与高质量发展知识图谱构 建与科学问题挖掘研究; 陕西省创新能力支撑计划软科学研究项目 (2020KRM022): 陕西工业遗产地域形象研究。 
知识图谱与文献计量作为近年来科学计量学的新兴热门研究方法, 常被应用于挖掘探究一个学科领域的能量 分布特征、学科知识演化态势、研究热点主题以及潜在前沿趋势等 ${ }^{[7]}$ 。当前, 国内外常见的文献可视化工具主要有 CiteSpace、VOSviewer、NetDraw、HistCite、Pajek、Sci2、BibExcel、Bicomb、Ucinet等诸多种，这些方法各具优缺 点。相较之下, 美籍华人陈超美开发出了文献计量与可视化软件CiteSpace, 以其可视化效果好、数据分析量大等优点 著称, 是当前文献计量与可视化的主流分析平台 ${ }^{[8]}$ 。城市绿化领域的文献计量分析主要集中在某一特定主题的常规性

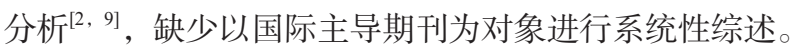

本研究从知识图谱的视角, 对UFUG所刊发论文进行系统性分析, 有助于综合呈现城市林业与城市绿化领域的原 创性研究成果, 评估对该领域的最新研究进展的共识或缺乏共识的程度, 并确定挑战和未来的方向。多维度、系统性 地地呈现系统性文献综述的主要信息, 并能够通过图层叠置, 直观地表达各层级之间关系, 能够为交叉学科研究提供 理论指导和思维启发。

\section{二、数据来源与分析方法}

(一) 文献数据获取

2020年7月29日在Web of Science核心合集 $($ WoS ) 中通过检索式 (期刊名称 = “Urban Forestry \& Urban Greening” ), 共检索到1434篇, 通过CiteSpace.5.6.R3 (https://sourceforge.net/projects/citespace/) 除重分析后, 最终得 到1382篇文献信息。

\section{（二）文献计量分析与可视化}

根据已有研究提出的知识图谱分析方法 ${ }^{[8]}$, 本研究运用CiteSpace. 5.6.R3 对文献进行不同节点的网络可视化分析, 分析参数设置参考张新平等 ${ }^{[10]}$ 的研究方法。借助发文量、被引频次、 $\mathrm{h}$ 指数 ${ }^{[11]}$ 等文献计量指标分析学术影响力, 同时 评述高被引用文献 ${ }^{[12]}$ 、关键文献 ${ }^{[13]}$ 和经典文献 ${ }^{[14]}$ 。文献地理分布特征研究通过国家 (地区) 节点分析实现, 文献数据 的分布图在Origin Pro 2015中完成。

\section{三、结果与分析}

（一）国际城市绿化论文研究现状

1. 发文量年际变化趋势

图1表明, UFUG文献年文献量增长模型是以开口向下的抛物线为指数的复合指数函数, 依据模型的预测结果可 知, UFUG年文献量将在2026年达到峰值286篇、总文献量将达到2570篇, 累计文献量将在2050年达到高峰值4966篇, 在未来30年内, 国际对城市林业与城市绿化研究的关注度将不断提高。 $\mathrm{h}$ 指数呈先升后降趋势, 篇均被引频次呈持续 下降趋势，这可能与UFUG年发文量的递增和选题多元化有关。

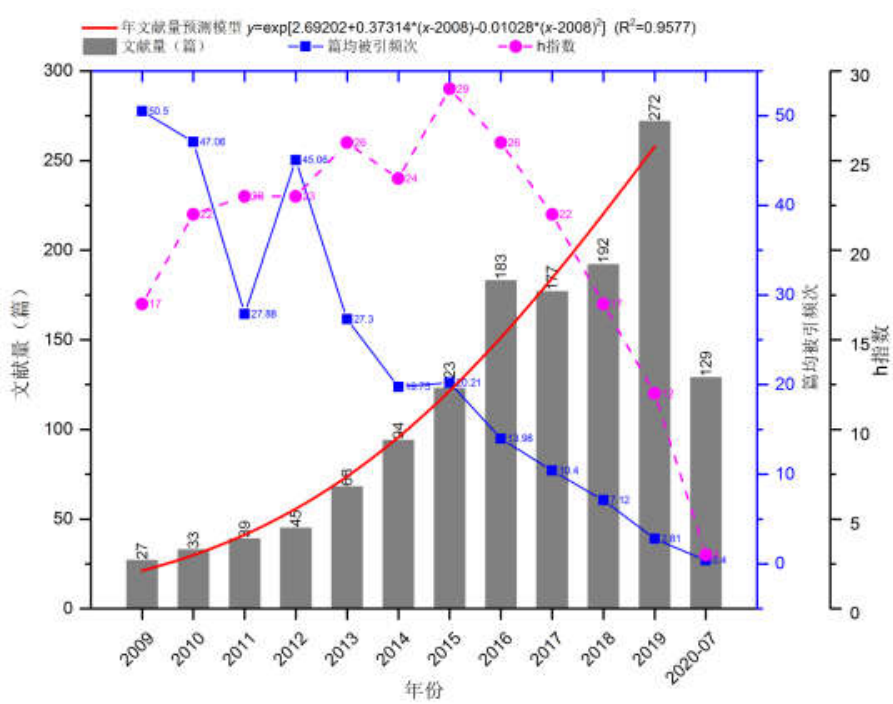

图1 国际期刊UFUG论文数量与影响力年际变化趋势

2. 研究机构与核心作者 
由表1可知, UFUG中的1382篇论文由1363个研究机构和3561位作者共同完成, 发文量前10位的研究机构与核心作 者中, 美国占了一半以上, 其次为中国和欧洲国家, 表明这些国家较重视城市林业与城市绿化研究工作, 具有长期坚 持的科研团队。

\section{表1 发文量前10位的研究机构与核心作者}

\begin{tabular}{|c|c|c|c|c|c|c|c|c|}
\hline \multirow{2}{*}{ 序号 } & \multicolumn{4}{|c|}{ 研究机构 } & \multicolumn{4}{|c|}{ 核心作者 } \\
\hline & 研究机构 & 文献量 & 篇均被引频次 & h指数 & 作者 ( 研究机构 ) & 文献量 & 篇均被引频次 & h指数 \\
\hline 1 & 美国农业部 & 67 & 16.91 & 17 & JIM C Y ( 香港大学 ) & 20 & 24.15 & 12 \\
\hline 2 & 瑞典农业科学大学 & 64 & 17.39 & 16 & NOWAK D J（美国农业部） & 15 & 19.73 & 7 \\
\hline 3 & 美国林务局 & 64 & 17.39 & 16 & $\begin{array}{c}\text { VAN DEN BOSCH CCK ( 不列颠哥伦 } \\
\text { 比亚大学) }\end{array}$ & 14 & 21.79 & 9 \\
\hline 4 & 哥本哈根大学 & 56 & 26.93 & 21 & KANE B (马萨诸塞州大学 ) & 14 & 2.93 & 4 \\
\hline 5 & 中国科学院 & 43 & 18.33 & 13 & KOESER A K ( 佛罗里达大学 ) & 13 & 3.54 & 5 \\
\hline 6 & $\begin{array}{c}\text { 佛罗里达州立大学 } \\
\text { 系统 } \\
\end{array}$ & 35 & 8.86 & 9 & PAULEIT S ( 慕尼黑工业大学) & 12 & 35.83 & 8 \\
\hline 7 & 佛罗里达大学 & 30 & 7.90 & 8 & KOWARIK I ( 柏林理工大学 ) & 12 & 24.42 & 8 \\
\hline 8 & 墨尔本大学 & 29 & 19.41 & 13 & ROMAN L A（美国农业部） & 12 & 11.92 & 6 \\
\hline 9 & 赫尔辛基大学 & 28 & 17.32 & 10 & MORGENROTH J（坎特伯雷大学） & 11 & 16.00 & 7 \\
\hline \multirow{3}{*}{10} & \multirow{3}{*}{ 香港大学 } & \multirow{3}{*}{26} & \multirow{3}{*}{22.92} & \multirow{3}{*}{14} & $\begin{array}{c}\text { ARNBERGER A (维也纳自然资源和 } \\
\text { 生命科学大学) }\end{array}$ & 10 & 28.00 & 8 \\
\hline & & & & & MCPHERSON E G（美国农业部） & 10 & 22.60 & 7 \\
\hline & & & & & SHACKLETON C M (罗德斯大学) & 10 & 15.70 & 6 \\
\hline 合计 & 1363 & 1382 & 13.94 & 56 & 3561 & 1382 & 13.94 & 56 \\
\hline
\end{tabular}

\section{3. 研究空间分布特征}

图2表明，UFUG中的1382篇论文来自86个国家和地区，其中68个国家和地区间有合作关系（图4 ），发文量前 10位的国家为图2中含有蓝色备注的国家。连线数目代表与其他国家的合作关系，连线的宽度代表它们之间的合作强 度, 由此可见, 合作网络发达程度前5位的国家分别为: 美国、加拿大、英国、澳大利亚、中国; 合作强度较高的国 家组合有：芬兰与德国、德国与瑞典、澳大利亚与巴基斯坦、法国与加拿大、智利与越南、法国与葡萄牙等。

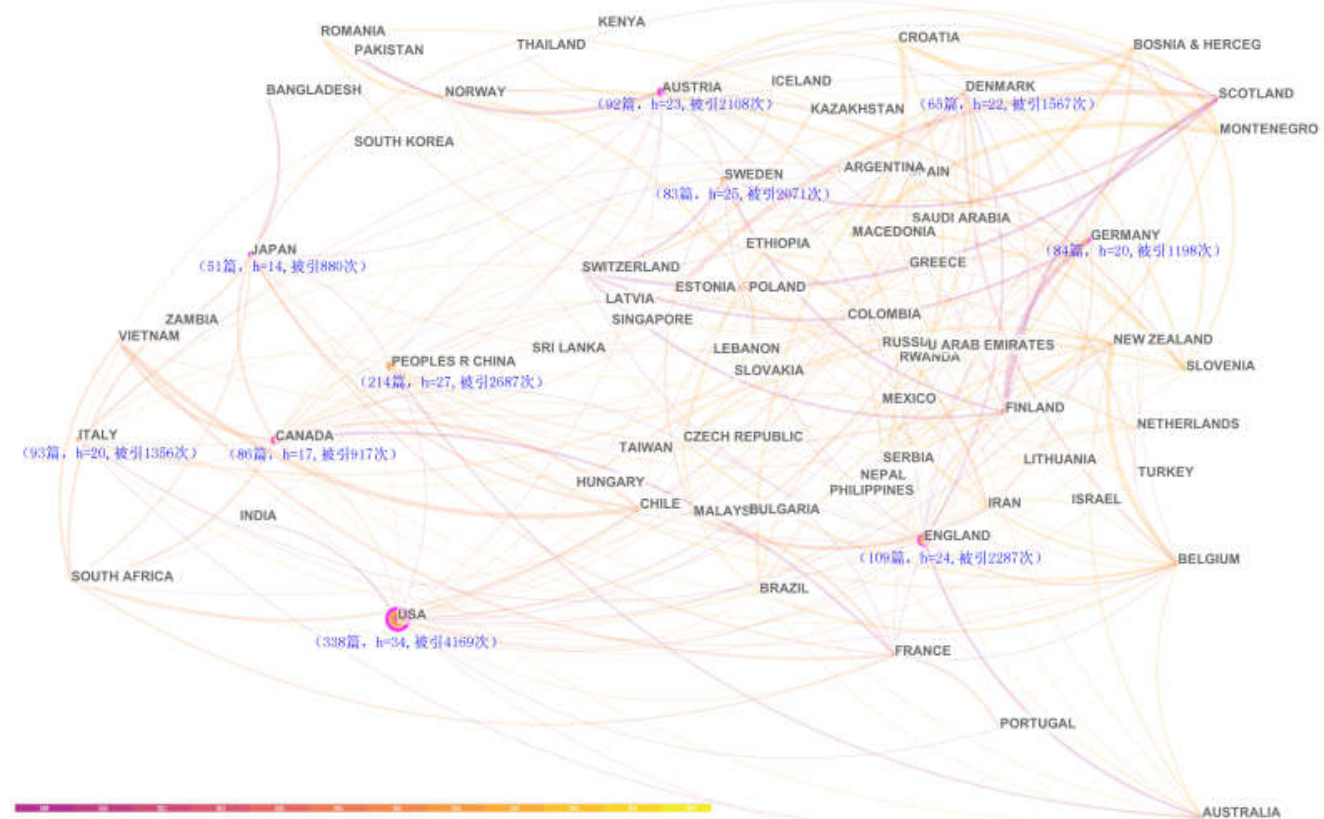

4. 经典研究文献 
表2呈现了UFUG所发表的论文的共被引网络谱图中具有引用爆发量的前40项文献（经典文献）的基本信息，包括 作者、年份、期刊名称、卷、期、DOI号 (含网址超链接) 和引用量爆发起止时间，便于该领域学者查阅学习。

表2 基于网络中介中心性识别出UFUG中的经典文献 (40项)

\begin{tabular}{|c|c|c|c|}
\hline 参考文献 & 强度 & 起始 & 结束 \\
\hline Yang J, 2005, URBAN FOR URBAN GREE, V3, P65-78, DOI & 3.02 & 2009 & 2012 \\
\hline Chiesura A, 2004, LANDSCAPE URBAN PLAN, V68, P129-138, DOI & 4.51 & 2009 & 2011 \\
\hline James P, 2009, URBAN FOR URBAN GREE, V8, P65, DOI & 4.33 & 2009 & 2011 \\
\hline Tzoulas K, 2007, LANDSCAPE URBAN PLAN, V81, P167-178, DOI & 3.65 & 2009 & 2014 \\
\hline Konijnendijk CC, 2003, FOREST POLICY ECON, V5, P173-186, DOI & 2.81 & 2009 & 2011 \\
\hline Grahn Patrik, 2003, URBAN FORESTRY \& URBAN GREENING, V2, P1-18, DOI & 5.07 & 2009 & 2011 \\
\hline Alvey Alexis A, 2006, URBAN FORESTRY \& URBAN GREENING, V5, P195-201, DOI & 3.12 & 2009 & 2013 \\
\hline van den Berg AE, 2007, J SOC ISSUES, V63, P79-96, DOI & 2.81 & 2009 & 2011 \\
\hline Tyrvainen L, 2005, URBAN FORESTS TREES, V0, P81-114, DOI & 4.33 & 2010 & 2013 \\
\hline Troy AR, 2007, ENVIRON MANAGE, V40, P394-412, DOI & 3.33 & 2011 & 2014 \\
\hline Nowak David J, 2006, URBAN FORESTRY \& URBAN GREENING, V5, P93-103, DOI & 5.67 & 2011 & 2014 \\
\hline Velarde M D, 2007, URBAN FORESTRY \& URBAN GREENING, V6, P199-212, DOI & 3.91 & 2011 & 2015 \\
\hline KONIJNENDIJK CC, 2008, FOREST CITY CULTURAL, V0, P0, DOI & 3.80 & 2011 & 2013 \\
\hline Gill SE, 2007, BUILT ENV, V33, P115-133, DOI & 4.38 & 2011 & 2015 \\
\hline Conway Tenley M, 2007, URBAN FORESTRY \& URBAN GREENING, V6, P181-192, DOI & 3.70 & 2011 & 2014 \\
\hline Konijnendijk Cecil C, 2006, URBAN FORESTRY \& URBAN GREENING, V4, P93-103, DOI & 3.33 & 2011 & 2014 \\
\hline Fuller RA, 2007, BIOLOGY LETT, V3, P390-394, DOI & 2.77 & 2012 & 2015 \\
\hline Thaiutsa Bunvong, 2008, URBAN FORESTRY \& URBAN GREENING, V7, P219-229, DOI & 3.34 & 2012 & 2014 \\
\hline Nagendra H, 2010, URBAN FOR URBAN GREE, V9, P129-137, DOI & 3.76 & 2012 & 2014 \\
\hline Grove JM, 2006, ECOSYSTEMS, V9, P578-597, DOI & 4.18 & 2012 & 2014 \\
\hline Chang CR, 2007, LANDSCAPE URBAN PLAN, V80, P386-395, DOI & 2.92 & 2012 & 2014 \\
\hline Oberndorfer E, 2007, BIOSCIENCE, V57, P823-833, DOI & 3.34 & 2012 & 2014 \\
\hline Nowak D J, 2007, URBAN COMMUNITY FORE, V0, P25-46, DOI & 3.05 & 2012 & 2015 \\
\hline Bjerke Tore, 2006, URBAN FORESTRY \& URBAN GREENING, V5, P35-44, DOI & 3.13 & 2012 & 2013 \\
\hline Boone Christopher G, 2010, URBAN ECOSYSTEMS, V13, P255-271, DOI & 2.86 & 2013 & 2014 \\
\hline Nowak David J, 2008, Arboriculture \& Urban Forestry, V34, P347-358 & 3.25 & 2013 & 2014 \\
\hline Maas J, 2006, J EPIDEMIOL COMMUN H, V60, P587-592, DOI & 2.86 & 2013 & 2014 \\
\hline Armson D, 2012, URBAN FOR URBAN GREE, V11, P245-255, DOI & 3.03 & 2013 & 2015 \\
\hline Fuller RA, 2009, BIOL LETTERS, V5, P352-355, DOI & 2.70 & 2014 & 2015 \\
\hline Adevi AA, 2013, URBAN FOR URBAN GREE, V12, P230-237, DOI & 2.70 & 2014 & 2015 \\
\hline Guitart D, 2012, URBAN FOR URBAN GREE, V11, P364-373, DOI & 2.65 & 2015 & 2016 \\
\hline McKinney M L, 2008, URBAN ECOSYSTEMS, V11, P161-176, DOI & 3.32 & 2015 & 2016 \\
\hline R Core Team, 2014, R LANG ENV STAT COMP, V0, P0, DOI & 3.32 & 2015 & 2016 \\
\hline Jim CY, 2008, J ENVIRON MANAGE, V88, P665-676, DOI & 3.32 & 2015 & 2016 \\
\hline Wolch JR, 2014, LANDSCAPE URBAN PLAN, V125, P234-244, DOI & 4.69 & 2016 & 2017 \\
\hline Hartig T, 2014, ANNU REV PUBL HEALTH, V35, P207-228, DOI & 3.37 & 2016 & 2017 \\
\hline Kowarik I, 2011, ENVIRON POLLUT, V159, P1974-1983, DOI & 3.11 & 2016 & 2017 \\
\hline Goddard MA, 2010, TRENDS ECOL EVOL, V25, P90-98, DOI & 2.59 & 2016 & 2017 \\
\hline Nordh H, 2009, URBAN FOR URBAN GREE, V8, P225-235, DOI & 2.85 & 2016 & 2017 \\
\hline United Nations, 2014, WORLD URB PROSP 2014, V0, P0, DOI & 2.85 & 2016 & 2017 \\
\hline
\end{tabular}

（二）国际城市绿化论文研究热点和主要研究方向 


\section{1. 研究热点演进}

在CiteSpaceV基于 “词频*逆文档频率” ( TF*IDF ) 算法 ${ }^{[8]}$ 获得了UFUG所刊发论文研究的热点演进情况（图 3 ), 表明国际城市林业与城市绿化研究关键词网络图谱, 由 385 个节点 (关键词) 和 2366 条连线组成, 聚类成 8 个 组, 分别为:

（1）第一组（\#0 风景园林）, 包含的主要关键词（词频前20位, 下同）有：幸福、健康、维也纳、恢复环境、规 划/设计、口袋公园、树的寿命、降噪、园区设计、偏好、上班族、感知感官维度、森林游䪐活动、行道树、恢复性体 验、城市规划、案例研究、城市儿童园艺、自然游戏、热通量等。

（2）第二组（\#1 雷达），包含的主要关键词有：城市林业、城市森林、城市树木、光检测与测距、异戊二烯、树 高、叶面积指数、树木保护、森林监测、树木生长、遗产树木 (古树名木) 、臭氧、异速生长、机载激光扫描、城市 可持续性、树异位测定法、i-tree canopy（树冠）等。

( 3 ) 第三组 (\#2 治理), 包含的主要关键词有: 政策、景观管理、经济价值、规划标准、城市政治生态、游咊行 为观察法 (SOPARC) 、分位数回归、公园、哥本哈根、支付意愿、城市森林、环境正义、人类健康、社会生态学关 系、叙述、可持续发展、费城、植树、冷岛效应、环境教育、投标动机、不透水表面积、经验的消失、绿地管理、俱 乐部物品、问卷调查、森林学校、社会生态模型、收人、都市自然、湿地管理、绿地规模、公众参与等。

（4）第四组（\#3 城镇化）, 包含的主要关键词有: 土地用途、城市生物多样性、生物均质化、城市生态、物种丰 富度、娱乐、城市树木、不同、自然公园、城市植物区系、多时间分析、河岸林、道路密度、城市遗迹、腐殖昆虫、 土地覆盖、林荫树、生态功能、主成分分析 ( PCA) 、鸟类一生境关系等。

（５）第五组（\#4 重金属）, 包含的主要关键词有: 生物监测、植物适应性、植物胁迫、圣栎 ( holm oak)、木材 强度、木材密度、液通量密度、PSII光化学、叶绿素苂光、害虫防治、气体交换、篮查技术、沉积、五角花、木材刚 度、叶状叶体、稳定同位素、集装箱生产、植物保健、营养、交叉耐受性等。

（6）第六组（\#5 调研）, 包含的主要关键词有：绿墙、绿色基础设施、绿色屋顶、城市植被、以社区为基础、 S-G滤波器、物候空间分布格局、评价、荒地-城市界面建筑风险指数（WUIBRI）、信仰、短柄假体、主机首选项、 地区、人格、割草、绿地规划、木本种、城市空气质量、物候特征、非原生森林害虫等。

( 7 ) 第七组 (\#6 城市规划), 包含的主要关键词有: 城市公园、行道树、二氧化碳封存经济价值、三维微气候模 型（Envi-met）、计算流体动力学 ( CFD ) 、基于对象的图像分割、气候变化适应、热应激、棕色屋顶、二氧化碳封 存、衬底深度、剑桥大学卡耐基陆地卫星分析系统lite (CLASlite)、伍德兰镇（The Woodlands Township）、平均辐 射温度、中暑、绿色屋顶、协同规划、热相关发病率、生态/活动屋顶 (eco-roof / living roof) 等。

（8）第八组（\#7 美学偏好），包含的主要关键词有：景观评估、教育和技术援助、花园损失、城市粮食安全、真 实感可视化、利益相关者网络、支持程序、自给自足、园林效率、判断一致、美学质量、景观类型、蔬菜、鲜花、园 艺、城市农业产量、城市园艺、挑战、障碍、都市农业、城市树木/森林/林业等。

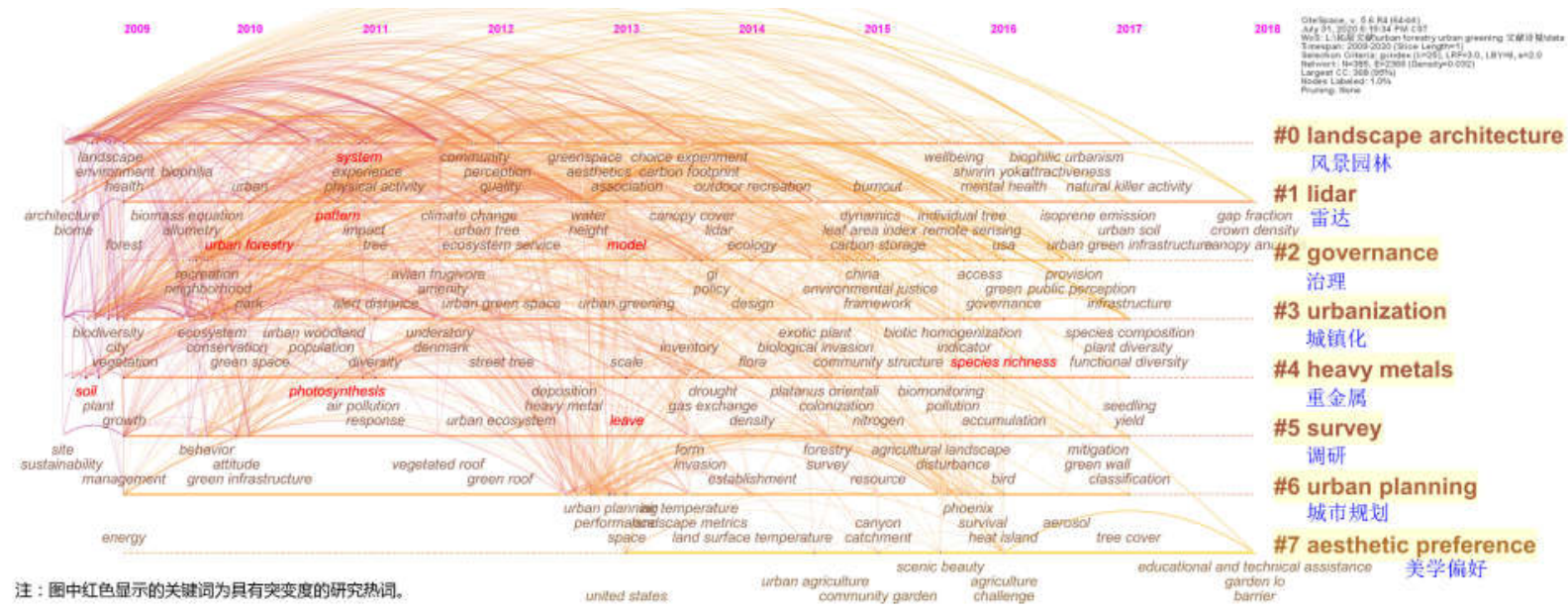

图3 国际期刊UFUG论文关键共现时线视图及研究热词 
由图2还可知，土壤（soil，2009-2011）、城市林业（urban forestry，2009-2011）、系统（ system，2011一 2014 ）、格局（pattern，2011－2014）、模型（ model，2013－2015）、叶片（leave，2013－2015）、光合作用 （ photosynthesis，2010-2013）、物种丰富度（ species richness，2016-2017）是UFUG学者群体中关注度较高的关键 词, 即研究热点。

\section{2. 研究参考文献来源分析}

图4呈现了国际期刊UFUG所引用的文献的来源期刊（476种）及其频次（11481次），其中引用频次前5位的期 刊分别为: Urban Forestry \& Urban Greening, Landscape and Urban Planning, Arboriculture \& Urban Forestry, Journal of Environmental Management, Arboriculture \& Urban Forestry, 累计被引用1955次, 占总被引频次的13.07\%。经过聚类分 析, 发现所引用的参考文献可以聚类为以下 8 类: 情绪、遥感、北方森林、生态学、条件价值评估、丹麦、预测噪声 衰减、欧洲白蜡。

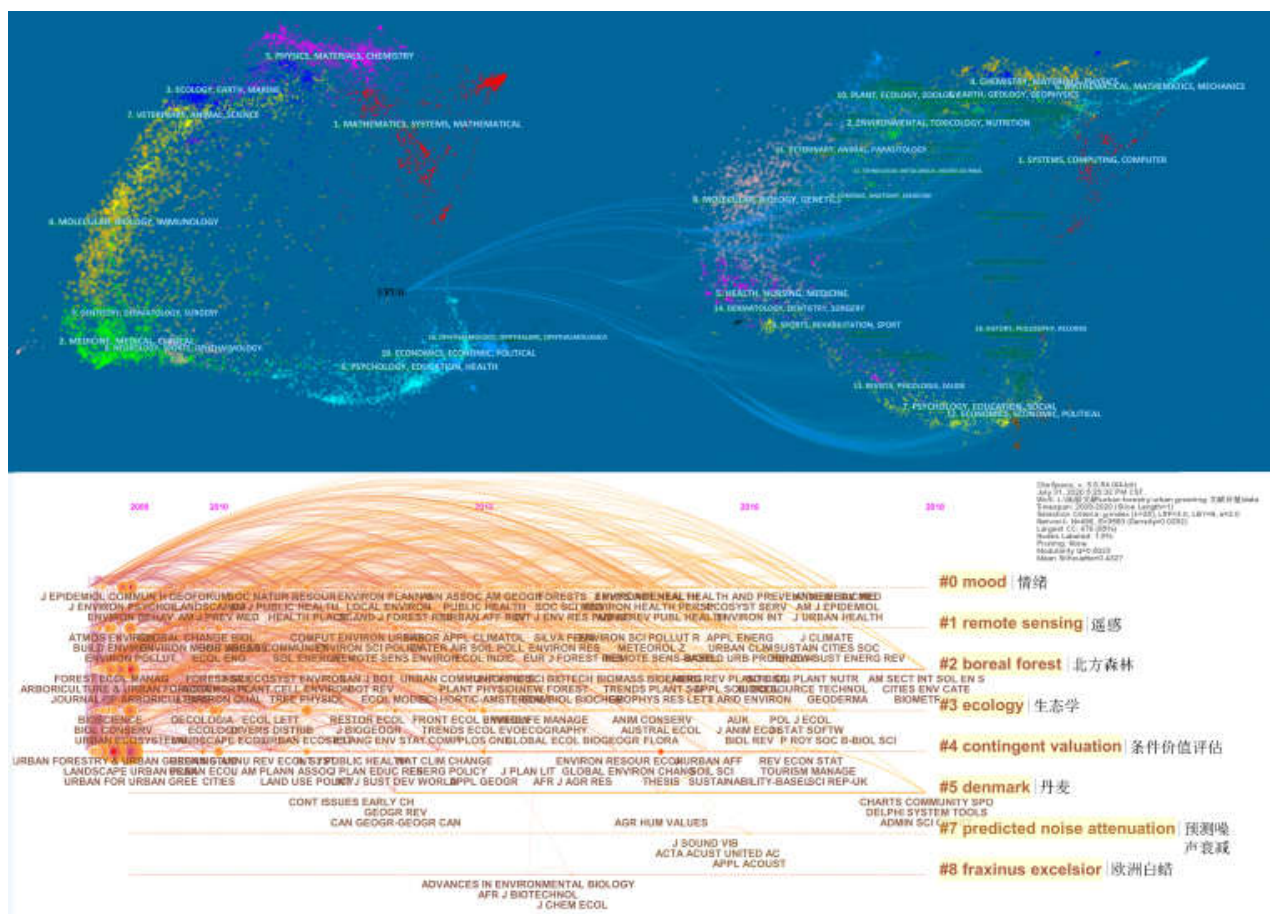

图4 国际期刊UFUG论文所引用的文献来源期刊叠置网络

表3列出了UFUG发表论文中, 具有引用量爆发值的前29位期刊的基本信息, 包括期刊中引文名称、引用热度持续 时间、引用量爆发强度。这些期刊是国际城市绿化的研究的最主要一次文献 (引用文献 ) 来源。

表3 国际期刊UFUG论文所引用的频次较高的文献来源期刊（TOP29）

\begin{tabular}{|c|c|c|c|}
\hline 起始 & 结束 & 强度 & 被引文献来源 \\
\hline 2009 & 2012 & 9.0268 & URBAN FORESTRY \& URBAN GREENING城市林业与城市绿化 \\
\hline 2009 & 2012 & 8.7347 & Journal of Arboriculture/树木栽培学杂志 \\
\hline 2010 & 2013 & 5.0010 & J FOREST/林业杂志【英国】 \\
\hline 2010 & 2012 & 4.9357 & EXPERIENCE NATURE PS/体验自然个人游记 \\
\hline 2009 & 2011 & 4.8667 & BIODIVERS CONSERV/生物多样性保护 \\
\hline 2011 & 2015 & 4.6284 & HYDROL PROCESS/水文过程 \\
\hline 2011 & 2013 & 4.2166 & FOREST CITY CULTURAL/森林城市文化 \\
\hline 2010 & 2012 & 4.0392 & ENVIRON BEHAV/环境与行为 \\
\hline 2011 & 2013 & 3.8893 & SOC NATUR RESOUR/社会与自然资源 \\
\hline 2009 & 2011 & 3.8196 & J ARBORICULT/树木学杂志 \\
\hline 2009 & 2012 & 3.8146 & J SOC ISSUES/社会问题杂志【美国】
\end{tabular}


续表:

\begin{tabular}{|c|c|c|c|}
\hline 起始 & 结束 & 强度 & 被引文献来源 \\
\hline 2011 & 2014 & 3.7006 & BIOTROPICA/热带生物学 \\
\hline 2009 & 2014 & 3.6915 & FORESTRY/林学 \\
\hline 2011 & 2013 & 3.6891 & SCAND J PSYCHOL/斯堪的纳维亚心理学杂志 \\
\hline 2013 & 2014 & 3.5943 & PLANT PHYSIOL/植物生理学 \\
\hline 2011 & 2014 & 3.2891 & THESIS SWEDISH U AGR/瑞典农业大学学位论文 \\
\hline 2009 & 2012 & 3.1762 & J LEISURE RES/休闲研究杂志 \\
\hline 2010 & 2013 & 3.0121 & URBAN ECOL/城市生态 \\
\hline 2010 & 2013 & 3.0048 & LAND ECON/土地经济学 \\
\hline 2012 & 2015 & 2.9630 & CAN J BOT/加拿大植物学杂志 \\
\hline 2010 & 2011 & 2.8796 & J ENVIRON ECON MANAG/坏境经济与管理杂志 \\
\hline 2009 & 2010 & 2.8540 & URBAN FORESTRY PLANN/城市林业规划 \\
\hline 2012 & 2013 & 2.8313 & CAN GEOGR-GEOGR CAN/加拿大地理学家 \\
\hline 2009 & 2011 & 2.8178 & Journal of Environmental Horticulture/不境园艺学杂志 \\
\hline 2009 & 2013 & 2.6805 & CHICAGOS URBAN FORES/芝加哥城市森林 \\
\hline 2010 & 2013 & 2.6625 & FOREST SCI/林业科学【英国】 \\
\hline 2010 & 2011 & 2.6602 & FUNCT ECOL/功能生态学 \\
\hline 2011 & 2013 & 2.6344 & FAO IRRIGATION AND DRAINAGE PAPER/粮农组织灌溉和排水论文 \\
\hline 2009 & 2010 & 2.5792 & ECOL ECON/生态经济 \\
\hline
\end{tabular}

3. 主要研究子领域述评

(1) 城市树木效益与成本评估研究

(1) 城市树木效益

综合已有研究从社会、经济、健康、视觉美学四个维度，列举了城市树木效益评估的常用二级指标 (表4)。

表4 城市树木效益评估的维度

\begin{tabular}{|c|c|}
\hline 一级指标 & 二级指标 \\
\hline 社会效益 & $\begin{array}{c}\text { 使城市环境更宜于生活、工作和度过闲暇时间; 提供有意义的户外休闲娱乐与体验自然的机会; 在城市中提供自 } \\
\text { 然要素与氛围; 提高城市生活质量; 推广环保责任及道德; 社区的社会认知与自尊的意识; 为重要的情感和体验提供环境 } \\
\text { 视 }\end{array}$ \\
\hline 经济效益 & $\begin{array}{c}\text { 持续性地节省大量燃料开支; 增加土地价值; 增加固定资产 (房产) 价值; 增加租金; 增加邻近物业价值; 减少 } \\
\text { 出售财产的 “上市时间” ; 增加财产税; 增加旅游收人; 增加商业活动; 激活城市经济的活力; 提高市政投资的 } \\
\text { 年度收益; 减轻城市内低收人群体的生活困难; 减少空气污染消除方面的开支; 减少雨水基础设施的开支; 节省 } \\
\text { 每年供热和制冷费用; 节省电费; 避免投资新电源; 为未来的碳排放补偿贸易提供潜力 }\end{array}$ \\
\hline 健康效益 & $\begin{array}{c}\text { 在医院里有树景的窗户可以降低并发症, 并有助于快速康复; 减少压力; 改善身体健康; 创造轻松的心理状态; } \\
\text { 避免过早死亡; 避免呼吸系统疾病住院 }\end{array}$ \\
\hline 视觉与美学效益 & 提供一种地方感和认同感; 通过突出季相变化来创造季节性兴趣; 改善风景质量; 提供隐私空间 \\
\hline
\end{tabular}

(2) 城市树木提供的生态系统服务

表5 城市树木生态系统服务评估的常用指标

\begin{tabular}{|c|c|}
\hline 一级指标 & 二级指标 \\
\hline 碳相关的 & 存储或固定碳 \\
\hline 空气质量 & 固碳释氧; 过滤空气 $\left(\right.$ 去除 $\mathrm{O}_{3} 、 \mathrm{CO} \mathrm{SO}_{2} 、 \mathrm{NO}_{2}$ 等 $) ;$ 去除悬浮颗粒物; 滞尘; 除雾 \\
\hline 暴雨洪水 & 减少雨水径流率; 减少雨水径流量; 减少洪灾损失; 减少水质问题; 补给地下水 \\
\hline 节约能源 & 减少每年的能源消耗; 减少夏季的能源使用量; 减少季节性降温能量; 减少发电厂的 $\mathrm{CO}_{2}$ 排放 \\
\hline 提供生境 & 为野生动物提供栖息地; 加强生物多样性; 为城市生态系统提供稳定性 \\
\hline 减弱噪声 & 减少噪声; 减少明显的响度 \\
\hline 营造小气候 & 提供阴凉; 减少太阳辐射; 改善小气候; 降低相对湿度; 降低空气温度; 减少热岛效应; 减少眩光/反射; 控制风 \\
\hline
\end{tabular}


综合前人研究从碳、空气质量、雨洪、能源、噪声、小气候等维度, 列举了城市树木生态系统服务评估的常用二 级指标 (表5)。

(3) 城市树木的负面影响

综合相关研究报道从社会、经济、健康、视觉美学、环境、成本与支出等方面, 整理出了城市树木的负面影响评 估的常用二级指标 (表6)。

表6 城市树木的负面影响评估的常用指标

\begin{tabular}{|c|c|}
\hline 一级指标 & 二级指标 \\
\hline 社会问题/危害 & 引起对犯罪的恐惧; 引起对疾病的恐惧; 引起对昆虫和其他动物的恐惧; 引起对树木、森林等环境的恐惧 \\
\hline 健康问题/危害 & 植物花粉过敏症增加; 越来越多的相关昆虫和其他动物的攻击 \\
\hline 视觉和美学问题/危害 & $\begin{array}{c}\text { 黑暗; 不喜欢的杂乱无章会模糊好的视野; 在停放的车辆上滴下汁液或黏性残留物; 树木养护管理不到位, } \\
\text { 景观效果较差 }\end{array}$ \\
\hline 环境问题/危害 & $\begin{array}{c}\text { 树木管护消耗水与其他能源; 产生花粉; 生成绿色废物; 景观管理和树木管护排放碳; 产生和释放挥发性有 } \\
\text { 机化合物; 取代本地物种; 减少太阳光照射范围与时间; 掉落树枝、叶子、花朵和种子; 树根挤裂人行道; } \\
\text { 引起排水问题; 倒伏会破坏电力和交通等设施 }\end{array}$ \\
\hline 成本和支出 & $\begin{aligned} \text { 种植和建立成本; 灌溉成本; 养护管理成本; 维持城市野生动物的相关成本; 与森林引起的城市基础设施维 } \\
\text { 修有关的费用; 与太阳能收集器堵塞有关的成本 }\end{aligned}$ \\
\hline
\end{tabular}

（2）城市绿化相关的模型

综合已有研究 ${ }^{[15]}$, 表7呈现了城市绿化领域使用广泛的数值模型，他们可以 大致分为三类:

(1) 通用模型, 如城市微气候模拟模型 (ENVImet)、计算流体动力学 (CFD), 绿簇热时间常数 (Green CTTC ），DOE-2建筑能源模拟程序（DOE-2），太阳和长波环境辐照几何（SOLWEIG）。

(2) 城市森林特定模型（i-Tree, CITYgreen）。

(3) 景观连通性网络分析分析模型 (Conefor)。

表7 主要城市森林数值模型及其特征

\begin{tabular}{|c|c|c|c|c|c|c|}
\hline 模型 & 初始发布及当前版本 & 子模块与网址 & $\begin{array}{l}\text { 用户编程知识需 } \\
\text { 求状况 } \\
\end{array}$ & 是否开源/免费 & 不确定性评估 & 是否空间显式 \\
\hline i-Tree & 1996; Version 6 & $\begin{array}{c}\text { 生态、水文、街道、物种、树 } \\
\text { 冠、设计、景观等https://www. } \\
\text { itreetools.org }\end{array}$ & 低 & 否/是 & 有限制 & 是 \\
\hline ENVI-met & $\begin{array}{c}\text { 1994; Version } 4.3 \\
\text { (2017.11) } \\
\end{array}$ & $\begin{array}{l}\text { 大气、植被、土壤、建筑环境、 } \\
\text { 建筑体系http://www.envi-met.com }\end{array}$ & 低 & 否/是 & 有限制 & 是 \\
\hline CFD & $\begin{array}{l}\text { 2004; Version } 1712 \\
\text { (2017.12) }\end{array}$ & \begin{tabular}{|c|}
$\begin{array}{c}\text { Open Field Operation and } \\
\text { Manipulation (OpenFOAM) http:// } \\
\text { www.openfoam.com }\end{array}$ \\
\end{tabular} & 高 & 是/是 & 有限制 & 是 \\
\hline CFD & 1981; Version 2018 & $\begin{array}{c}\text { CHAM' } \begin{array}{c}\text { s PHOENICS http://www. } \\
\text { cham.co.uk/ }\end{array} \\
\end{array}$ & 中等 & 否/否 & 有限制 & 是 \\
\hline CITY-green & $\begin{array}{c}\text { 1996; Version } 5 \\
\text { (2004.03) }\end{array}$ & 无 & 低 & 否/是 & 无 & 否 \\
\hline Green CTTC & 2002; 无 & 无 & 无 & 无 & 有限制 & 否 \\
\hline DOE-2 & $\begin{array}{c}\text { 1978; Version } 2.3 \\
\text { (2017.07) } \\
\end{array}$ & 无; http://doe2.com & 中等 & 否/是 & 有限制 & 否 \\
\hline SOLWEIG & $\begin{array}{l}\text { 2008; Version 2016a } \\
(2016.09)\end{array}$ & $\begin{array}{c}\text { 无; http://www.urban-climate.net/ } \\
\text { content }\end{array}$ & 中等 & 是/是 & 有限制 & 是 \\
\hline Conefor & $\begin{array}{l}\text { 2006; Version2.6 } \\
(2012.04)\end{array}$ & $\begin{array}{c}\text { 生境斑块、空间距离等; http:// } \\
\text { www.conefor.org }\end{array}$ & 无 & 否/是 & 有限制 & 是 \\
\hline
\end{tabular}

(3) 城市树木生态学关注的其他方面

主要体现在种群特征、树种选择和其他生态问题等方面。

(1) 种群特征方面主要有: 行道树种群分析; 行道树种群生物多样性的评估和管理; 行道树种群多样性和稳定性; 城市森林结构评价; 景观树木的多样性和分布; 城市道路和公园树木的森林结构比较; 城市树木覆盖度/城市森林冠层 覆盖度的测量与分析; 树木评价方法比较; 行道树叶面积确定; 林分特征估算; 园林和行道树的时空变化; 树冠的绿 


\section{量衡量等。}

(2) 树种选择方面主要有: 行道树的选择过程; 城市树木种群抽样; 气候变化背景下预测树种的可用性; 树木和鲜 花作为街道植被元素的偏好; 树木生长、城市森林结构与大气污染去除间的关系; 预测行道树的结构参数 (直径、高 度、冠宽和叶面积等）; 树木生长与死亡, 高度直径关系; 估算叶面积和叶生物量; 城市树木的规划与管理; 人工预 测树形态参数等。

(3) 其他生态问题, 如, 行道树特征与城市鸟类利用的关系; 城市环境对森林的影响; 行道树的压力环境; 碳信用 的质量；城市森林可持续性指标；物种多样性与树种、昆虫种类之间的关系等。

(4) 社会生态学视角下城市绿化的研究范式

该范式从个人、社会、物理及其他因子 (可以根据实际情况进行增减与拓展) 等维度, 多方面地对城市建成绿化 空间或拟建设项目进行积极影响与消极影响评估和权衡，为城市绿化更新提供决策依据 ${ }^{[16]}$ ( 图 5 )。在这一框架下, 中国暨南大学学者武文杰研究团队, 基于北京中心城区提出了绿度、污染、幸福三者之间关系研究范式 ( 图6), 并 发现针对减轻特定领域的污染危害与改善绿色景观的政策是应共同塑造人们的生活质量 ${ }^{[17]}$, 该研究范式中引人了贝叶 斯多层有序响应模型 ${ }^{[18]}$

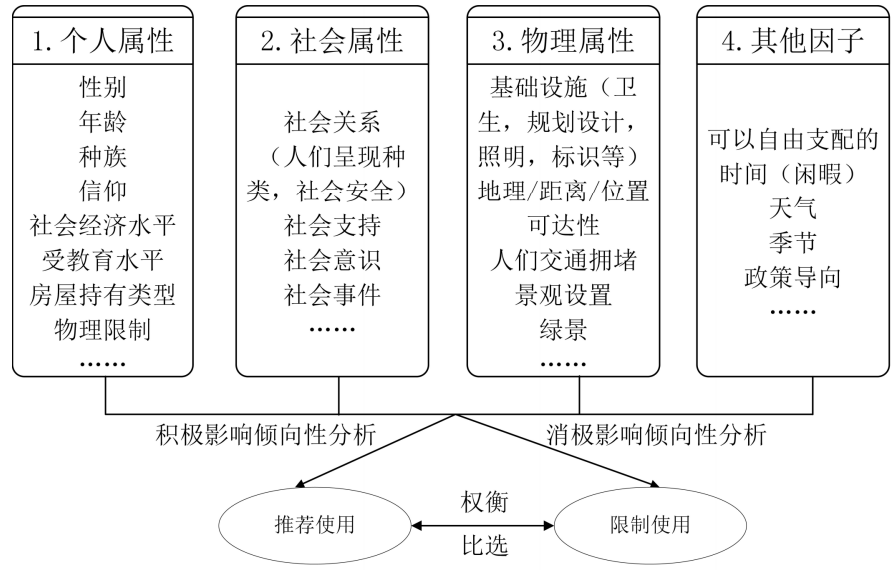

图5 城市绿化社会生态学研究范式 ( 笔者改绘)

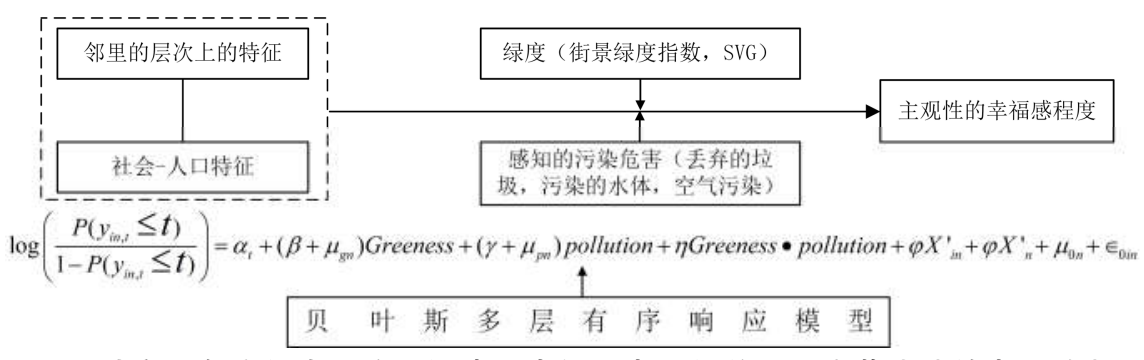

图6 城市绿色空间中绿度、污染、幸福三者之间关系研究范式（笔者改绘）

\section{四、结论与讨论}

本文从文献计量和可视化的角度，系统比较分析了国际SCI \& SSCI双检索期刊Urban Forestry \& Urban Greening所 刊载的1382篇文章的文献计量学特征, 得到的主要结论如下: 第一, 在未来30年内, 国际对城市林业与城市绿化研究 的关注度将不断提高。h 指数呈先升后降趋势，篇均被引频次呈持续下降趋势。第二，核心作者主要分布在美国、中 国和部分欧洲国家，美国、加拿大、英国、澳大利亚、中国是合作研究网络的核心成员。第三，识别出了 40 项经典 文献、8组研究热点关键词族群、8 个参考文献来源期刊族群。第四, 对 4 个主要研究子领域 (城市树木效益与成本评 估、城市绿化相关的模型、城市树木生态学关注的其他方面、社会生态学视角下城市绿化的研究范式）进行了评述。

由UFUG刊发论文所呈现出的知识图谱可以看出, 全球对城市林业与城市绿化的关注度在不断增强, 关注的领域 向多元化方向发展, 且倾向于热衷城市居民关切的生活相关的问题, 如公共健康、物种多样性、文化与生态服务、公 众参与等。虽然, 学术界对城市林业与城市绿化领域已经积累近半个世纪的研究经验, 但是, 由于该领域涉及诸多的 
自然学科与人文学科的交叉点, 至今仍未形成较为系统的学科体系, 需要全球城市林业与城市绿化的学者、实践者和 决策者们结合各国的实际和全球的整体形势，在人类命运共同体的理念下，为各国建设生态、宜居、健康城市提供智 力支持，并促成该领域学科体系的形成与完善。

\section{参考文献:}

[1][丹] S.E.约恩森(SvenErik Jøensen) 著,曹建军,赵斌,张剑,等译.生态系统生态学[M]北京:科学出版社, 2017.

[2]段振军.基于Web of Science的国际城市绿化研究知识图谱分析[J].南方园艺, 2020,31(04):65-69.

[3]张新平.景观用途棕地的识别评估及修复技术研究进展[J].陕西职业技术学院学报, 2016(4):45-48

[4]郑晓笛,吴熙.棕地再生中的生态思辨.中国园林, 2020,36(6):17-22.

[5]王得祥,张新平.城市森林建设理论与实践[M].杨凌:西北农林科技大学出版社, 2020.

[6]Urban Forestry \& Urban Greening官方网站[EB/OL]. https://www.journals.elsevier.com/urban-forestry-and-urbangreening, 2020-7-30

[7]CHEN C M, SONG M. Visualizing a Field of Research: A Methodology of Systematic Scientometric Reviews[J]. PLoS ONE, 2019,14(10):e0223994.

[8]陈悦,陈超美,刘则洲, 等.CiteSpace知识图谱的方法论功能[J].科学学研究, 2015,33(2):242-253.

[9]Shuvo F K, Feng X Q, Akaraci S, et al. Urban green space and health in low and middle-income countries: A critical review[J]. Urban Forestry \& Urban Greening, 2020,52:126662.

[10]张新平,王慧, 李睈, 等.近 30 年城市森林研究热点与前沿——基于CiteSpace的知识图谱分析 [J]. 中国城市林业, 2020,18(02):1-7.

[11]HIRSCH J E. An index to quantify an individual's scientific research output[J]. PNAS, 2005, 102(46): 16569-16572.

[12]TIJSSEN R J W, VISSER M S, VAN LEEUWEN T N. Benchmarking international scientific excellence: Are highly cited research papers an appropriate frame of reference?[J]. Scientometrics, 2002,54(3):381-397.

[13]张云,华薇娜,袁顺波.利用引文确定领域关键文献的方法探析[J].图书情报工作,2016,60(1):66-73,82.

[14]刘春艳.基于知识图谱的电子期刊研究领域可视化分析[J].情报杂志, 2011,30(S2):84-85,89.

[15]LIN J, KROLL C N, NOWAK D J, et al. A review of urban forest modeling: Implications for management and future research[J]. Urban Forestry \& Urban Greening, 2019,43:126366.

[16]PANEERCHELVAM P T, MARUTHAVEERAN S, MAULAN S, et al. The use and associated constraints of urban greenway from a socioecological perspective: A systematic review[J]. Urban Forestry \& Urban Greening, 2019,47:126508.

[17]WU W J, YUN Y W, HU B. et al. Greenness, Perceived Pollution Hazards and Subjective Wellbeing: Evidence from China[J]. Urban Forestry \& Urban Greening, 2020,56:126796.

[18]GOLDSTEIN, H., 2010. Multilevel Statistical Models, 4th Edition. John Wiley \& Sons, Ltd, pp. 15-72. https://doi. org/10.1002/9780470973394. 